\title{
A realidade tropical
}

\section{Francisco Alambert ${ }^{1}$}

\section{Resumo}

Dos anos 1960 até hoje, o Tropicalismo se tornou muito mais do que uma das últimas vanguardas modernistas ou a primeira pós-modernista - como se costuma repetir. Ele se firmou como uma espécie eficiente e reiterada de "razão" dualista para se definir a cultura brasileira e orientar sua produção (tanto estética quanto politicamente). $\mathrm{O}$ artigo procura analisar, a partir do momento atual de vitória (e crise) da lógica tropicalista, a história desse processo que lançou o Tropicalismo no centro do debate cultural contemporâneo, no Brasil e no exterior.

\section{Palavras-chave}

Tropicalismo, Caetano Veloso, cinema novo, Roberto Schwarz, artes plásticas.

Recebido em 7 de novembro de 2011

Aprovado em 8 de dezembro de 2011

I Professor do Departamento de História da USP. E-mail: alambert@usp.br 


\section{Tropical Reality}

\section{Francisco Alambert}

\section{Abstract}

Since the 1960s, Tropicalism has become much more than one of the final modernist/or first post-modern vanguards - as is so often said. The movement took hold as an efficient and reiterated form of dualist "reasoning" through which to define Brazilian culture and steer its production (both aesthetically and politically). The article aims to take the present moment of triumph (and crisis) in the Tropicalist logic as a platform from which to analyze the history of the process that launched Tropicalism into the heart of the contemporary cultural debate in Brazil and abroad.

\section{Keywords}

Tropicalism, Caetano Veloso, cinema novo, Roberto Schwarz, the plastic arts. 


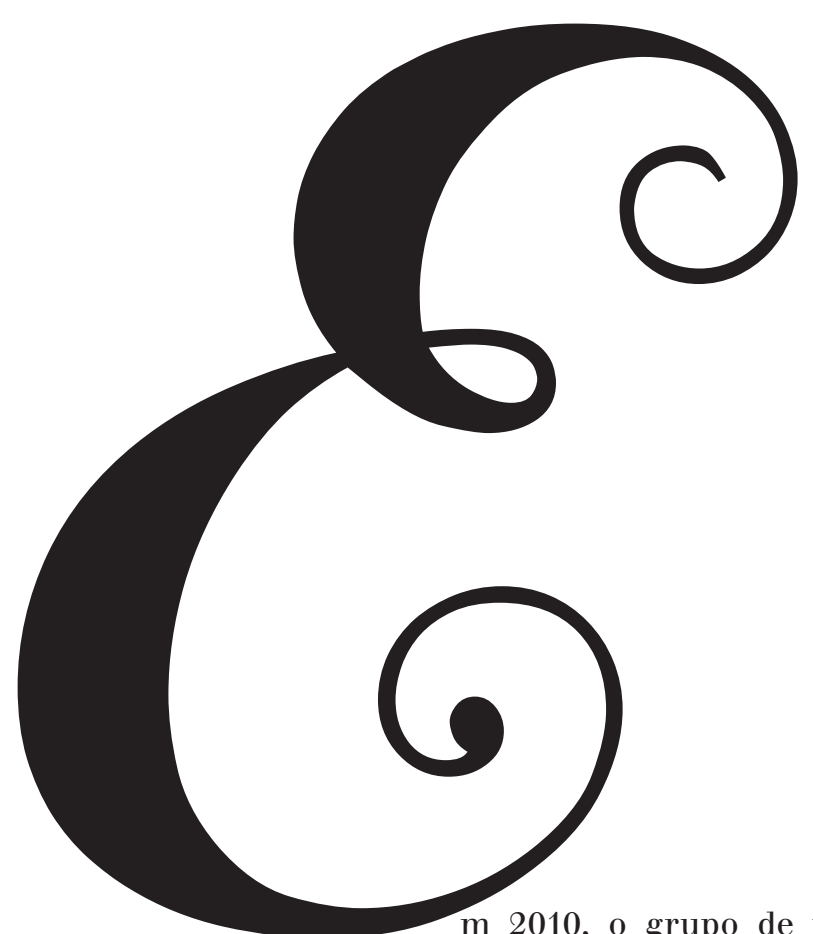

m 2010, o grupo de teatro paulistano Companhia do Latão estreou um espetáculo intitulado Ópera dos vivos. Nele, entre outras coisas, se procurava pensar cenicamente a história da esquerda no Brasil desde o início dos anos 1960 e seus embates e aporias diante da representação do país e de suas questões centrais, de um ponto de vista contemporâneo. O espetáculo divide-se em quatro partes tensamente relacionadas. Na primeira, o grupo encena a composição de uma ação e de um espetáculo relacionados às ligas camponesas e aos movimentos populares de cultura. Na segunda parte, assistimos a uma espécie de paródia, apresentada em filme, do clássico de Glauber Rocha Terra em transe, de 1967. Na terceira, vemos um show performático tropicalista. Na quarta, salta-se para um momento mais recente, em que a gravação de uma novela (cujo tema central é o romance entre uma militante política dos anos 1960 e um torturador) ocorre em uma emissora de televisão. Não faço aqui uma crítica do espetáculo, sequer me coloco a comentá-lo. Parto, entretanto, de uma cena específica, que creio servir de entrada para uma avaliação crítica do legado tropicalista diante das discussões sobre a cultura brasileira contemporânea.

Quase no final da referida paródia da ação tropicalista, o cantor-falador-pensador encaminha-se para sair de cena quando é questionado por um "velho" esquerdista que estaria presente na plateia. Ele para por um instante. Seu corpo está ligeiramente apontado para a saída, mas a cabeça voltada para o interlocutor. Uma postura olímpica. Neste

I4I

revista ieb $\quad$ n54 2012 set./mar. p. 139-150

RIEB54.indb 141

6/13/2012 3:25:45 PM 
momento, como se saísse do transe divertido e provocativo das performances aparentemente amalucadas a que assistíamos pouco antes, ele encarna um analista sóbrio, quase sisudo, de raciocínio cristalino e direto - até um tanto dogmático.

O que ele diz é mais ou menos o seguinte: Eu sei que a luta de classes acabou. Já me contaram que as coisas vão ser daqui por diante mais ou menos como nos Estados Unidos. Esquerda e direita são farinha do mesmo saco, e o nosso saco agora é outro. O mundo, esse grande saco, agora será ensacado na forma do que parecia ser a estrutura da sociedade norte-americana. O negócio agora é negar pela cultura (a contracultura), mirar nas minorias (os negros, os gays, a libertação sexual, o feminismo sem distinção de classe, só de gênero, etc.). E a gente não vai mais ao povo, a gente vai ao consumidor, através do espetáculo e da TV.

Tudo muito verdadeiro, plausível, realista e até generoso. Afinal, o que se diz poderia muito bem ser visto como a plataforma da nova esquerda, os imperativos de um marcusianismo tardio, uma deglutição, muito simplória é verdade, de uma certa verdade de 68 . O que não se diz (mas o engenho da cena demonstra) é que o palco dessa nova política agora é a televisão, a maior criação da ditadura militar, a cultura de massa (cuja face administrada e alienante a última parte do espetáculo do Latão demonstrará). O povo agora é massa, e essa massa é feliz. E o olhar contracultural apenas identifica na massa as suas partes minoritárias e busca trazê-las ao palco, mesmo que seja como mercadoria do espetáculo, que afinal de contas é algo que veio para ficar e de que o povo gosta.

Mas isso tudo é algo que se deduz. Porque depois do discurso afiado e sério, nosso pensador bicho-grilo, agora um ilustrado empresário de si mesmo e de seu espetáculo, sai da cena para não mais voltar. Quem voltará à cena, na parte derradeira da Ópera dos vivos, serão aqueles que o questionaram, aqueles derrotados desempregados, que se encontrarão no mesmo palco, quer dizer, na mesma TV que o tropicalista vaticinava como o novo palco da história sem classes, deleitado com a cultura de massas gerida pelos empresários golpistas. O cenário do Brasil delirantemente tropicalista do pós-68 está montado.

Podemos dizer, então, que o nosso pensador bicho-grilo sai do palco para entrar para a história. E a história que se segue, de lá para cá, é talvez o mais espetacular caso em que uma "vanguarda" se estabelece como regra, e jamais como exceção, durante mais de quarenta anos. Na verdade, o Tropicalismo, sua "razão", bem como sua forma se tornaram a figura dominante na cultura brasileira, chegando mesmo a se confundir com ela.

revista ieb $n_{54} 2012$ set./mar. p. I39-I5o 
Mais do que meramente "ideologia", o realismo tropicalista se tornou hegemonia. Entendo hegemonia como Raymond Williams:

todo um conjunto de práticas e expectativas, sobre a totalidade da vida: nossos sentidos e distribuição de energia, nossa percepção de nós mesmos e nosso mundo. É um sistema vivido de significados e valores - constitutivo e constituidor (...), um senso da realidade para a maioria das pessoas na sociedade, um senso de realidade absoluta, porque experimentada, e além da qual é muito difícil para a maioria dos membros da sociedade movimentar-se, na maioria das áreas de sua vida. ${ }^{2}$

Segundo este clássico do marxismo inglês, o poder hegemônico "não existe passivamente como forma de dominação. Tem de ser renovado continuamente, recriado, defendido e modificado. Também sofre uma resistência continuada, limitada, alterada, desafiada por pressões que não são as suas próprias pressões" .

Mas que essa digressão teórica não nos afaste da questão. Isto porque não creio estar falando em abstrato. $\mathrm{O}$ auge desse processo de conquista da hegemonia aconteceu em 2003, exatamente quando o PT, que nunca foi o Partido dos Tropicalistas (e sim, na sua origem, o partido de Mário Pedrosa, Antonio Candido ou Sérgio Buarque de Holanda, os intelectuais de esquerda que entediavam a nova vanguarda), chegou ao poder. Neste mesmo ano, Caetano Veloso cantou no Oscar. E Gilberto Gil virou ministro da Cultura Brasileira. A compoteira da "Geleia Geral brasileira/que o Jornal do Brasil anuncia" estava fechada.

Mais curioso ainda: nessa mesma época, sociólogos americanos invertiam o raciocínio do Caetano do Latão. Com a globalização e suas consequências, agora é o mundo que vai ficar parecido com o Brasil: Brazilianization $^{4}$. E se o Tropicalismo é a verdade da nossa cultura, então será também a verdade da cultura do novo mundo globalizado. Touché!

A pré-história disso remete ao clima de euforia, radicalismo, ilusões e liberdades democráticas que deram início à década de 1960 e dos quais o Tropicalismo é um legítimo herdeiro. Por exemplo, a dissidência Neoconcreta carioca das artes plásticas. Os neoconcretos procuravam elaborar uma arte que falasse à subjetividade, colocando o corpo como lugar privilegiado da narrativa, mas também aos problemas

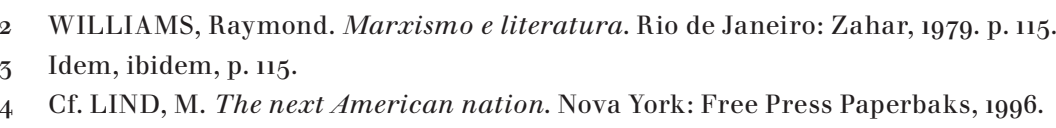


políticos gerais. Propunham potencializar os corpos e mentes para negar o mundo estabelecido - e não para melhor se estabelecer nele, como irá propor o realismo tropicalista. Os neoconcretos, a nova objetividade, os antecessores do Tropicalismo, se viam como propositores, mas como propositores de uma ação transformadora. Esta era a proposição de Lygia Clark em 1964:

Somos os propositores; somos o molde; a vocês cabe o sopro, no interior desse molde: o sentido da nossa existência. Somos os propositores: nossa proposição é o diálogo. Sós, não existimos; estamos a vosso dispor. Somos os propositores: enterramos a obra de arte como tal e solicitamos a vocês para que o pensamento viva pela ação. Somos os propositores: não lhes propomos nem o passado nem o futuro, mas o agora. ${ }^{5}$

Em seu manifesto "Esquema geral da Nova Objetividade", escrito logo depois, em 1967, Hélio Oiticica vai mais longe: "O fenômeno da vanguarda no Brasil não é mais hoje questão de um grupo provindo de uma elite isolada, mas uma questão cultural ampla, de grande alçada, tendendo às soluções coletivas" .

Oiticica vinha compondo uma série de obras, que não cabem ser comentadas aqui (parangolés, bólides, penetráveis), que davam forma a esse esquema. A mais famosa delas foi aquela que deu nome ao Tropicalismo, a Tropicália, de 1967. Tratava-se de um imenso penetrável, construído por uma estrutura sensorial, semelhante a um labirinto que conduz o participante por caminho surpreendente até chegar a um aparelho de televisão ligado (as semelhanças com a trajetória da Ópera dos vivos são inevitáveis). Sem entrar nos meandros da análise da obra, acredito que a TV representava um destino perigoso, que podia anular as experiências que a obra permitia. Ela era um imperativo (não se pode fugir da modernidade), mas também um objeto a ser criticado e não glorificado. Parece-me que o raciocínio tropicalista era exatamente o contrário disso.

Apesar de ter simpatizado imediatamente com o grupo tropicalista baiano, Oiticica, em um texto escrito para explicar a sua Tropicália, fez dura critica ao kitsch que o Tropicalismo exortava:

5 CLARK, Lygia. Nós somos os propositores, Livro-obra, 1964. Cf. DUNN, Christopher. Nós somos os propositores: vanguarda e contracultura no Brasil, 1964-1974. ArtCultura, Uberlândia, v. 10, jul-dez, 2008.

6 OITICICA, Hélio. Esquema geral da Nova Objetividade. In: BASUALDO, Carlos. Tropicália: uma revolução na cultura brasileira. São Paulo: Cosac Naify, 2007. p. 229. 
Burgueses, subintelectuais, cretinos de toda espécie, a pregar tropicalismo, tropicália (virou moda!) - enfim, a transformar em consumo algo que não sabem direito o que é... Muito bom, mas não se esqueçam que há elementos aí que não poderão ser consumidos por essa voracidade burguesa: o elemento vivencial direto, que vai além do problema da imagem... ${ }^{7}$

É em meio a esse complexo de ideias mais ou menos radicais, baseadas no desejo de explicação, conhecimento e crítica da "realidade nacional", que surgiu o Tropicalismo. No fim dos anos 1960, no auge da ação tropicalista, Roberto Schwarz lançou questões que até hoje circunscrevem parte sensível dos debates sobre o legado do movimento (e em muito orientaram a Ópera dos vivos). Na opinião do crítico, o Tropicalismo elaborava uma "dialética sem síntese", alegoria atemporal do país, que gira em falso (e se repete), criando a ideia de que o atraso e a confusão eram nosso destino e "diferença". O sarcasmo tropicalista ficaria nessa linha incerta entre "oportunismo e sensibilidade", entre "crítica e integração". Se o método Paulo Freire, também obra do "espírito" da redemocratização desenvolvimentista, seria político e propositivo, como o neoconcretismo, o Tropicalismo seria niilista. Se a Estética da Fome era um manifesto organizativo (estético e político) revolucionário, o Tropicalismo se comprazia no culto ao absurdo: a imagem tropicalista é o "ready made do mundo patriarcal e do consumo imbecil"s. E isso era um elogio - ou seja, para o crítico, essa imagem tinha um poderosíssimo caráter de intervenção e verossimilhança.

Décadas depois da crítica de Schwarz, Caetano Veloso, em seu livro Verdade tropical, reagiu de maneira inteligente e curiosamente lacunar. Relembrando a época em que leu o texto pela primeira vez, diz que "o artigo era interessante e estimulante", mas na verdade "uma versão complexa e aprofundada da reação desconfiada que a esquerda exibia contra nós", mesmo que o autor não demonstrasse "nem hostilidade (...) nem desprezo pelo nosso movimento". Impressionado que um pensador "de esquerda" pudesse "dar tanta e tão tenra atenção" à sensibilidade tropicalista, Veloso passa a anotar a surpresa que teve por Schwarz opor "o método de alfabetização Paulo Freire ao que os tropicalistas faziam: isso era exatamente uma repetição em sua teoria do que tinha acontecido em minha vida". Entretanto, ele afirma, sem explicar

7 OITICICA, Hélio. Esquema Geral. op. cit. p. 24,1.

8 Cf. SCHWARZ, Roberto. Cultura e política, 1964-1969. In: outros estudos. Rio de Janeiro: Paz e Terra, 1978. p. 78. O pai de família $e$ 
o motivo, que "sua redução da 'alegoria' tropicalista ao choque entre o arcaico e o moderno, embora revelasse aspectos até então impensados, resultava finalmente empobrecedora".

Caetano Veloso não explica o "empobrecimento", mas os acertos ou não da avaliação de Schwarz ainda hoje são motivo de controvérsia. O importante é acordar para o fato de que a "imagem" Tropicalista venceu, tornou-se uma espécie de ideologia oficial da cultura midiática brasileira do final do século XX. Hoje, o que nos interessa é justamente entender os vínculos dessa vitória espetacular que fez a pós-vanguarda dos anos 1960 se estabilizar como "verdade tropical".

Dez anos depois de Terra em transe e da explosão do Tropicalismo, Glauber Rocha ainda podia ver o movimento, que reivindicava seu filme como fundacional, com olhos generosos. Em uma entrevista à revista Veja em 1977 ele dizia:

Caetano criou o Tropicalismo como forma original de comportamento psicossocial - ele e Gil apareceram realmente com formas novas, coisas nossas, bossas nossas. Eles eram anti-Beatles, anti-Rolling Stones, eles eram a resposta, eram os Billy-the-Kid do subdesenvolvimento, a própria estética da fome em movimento, a própria antropofagia usando as guitarras eletrônicas para comer o bombardeio do rock e vomitar em formas novas, nítidas e revolucionárias o sentimento do povo brasileiro internacionalmente culto. ${ }^{10}$

Apenas três anos depois, em março de 1980, o cineasta concedeu outra entrevista, na qual só foi feita uma pergunta: "O que você tem a dizer sobre a questão das Patrulhas Ideológicas que vêm invadindo a imprensa e as paixões nesse último mês?". Foi o suficiente para que o entrevistado disparasse alucinadamente até o fim. A questão tratava de um tema candente na época da redemocratização dos anos 1980: o debate que dividiu os velhos militantes dos anos 1960 (sobretudo do Cinema Novo) quando Carlos Diegues atacou o que chamou de "patrulha ideológica" da esquerda à sua obra e à vida intelectual brasileira, no que foi seguido e apoiado por Caetano Veloso, entre outros.

Na entrevista, além de ajudar a reconstruir esse debate, Glauber marca uma posição contrária aos termos de Diegues e Veloso. E mais que isso, com uma lucidez impressionante mostra a afirmação de certo

9 VELOSO, Caetano. Verdade tropical. São Paulo: Companhia das Letras, 1997. p. 450.

10 ROCHA, Glauber. O sol ainda brilha? O décimo aniversário do Tropicalismo e as sombras que ameaçam cair sobre seus criadores, Veja, São Paulo, 23 nov. 1977. 
grupo no poder cultural - antecipando o processo que levaria a social-democracia ao poder político e que deixaria a indústria cultural no centro de toda a vida pública: o Cebrap

é cofinanciado ou patrocinado pela Fundação Rockfeller ou pela Fundação Ford (...), tem inclusive ligação com o liberalismo americano (...). Os liberais democratas do Brasil são apenas capitalistas progressistas ligados a multinacionais, que lutam contra o arcaísmo da economia política brasileira, que é a dominante. ${ }^{11}$

Seus antigos companheiros de Cinema Novo agora são o centro de uma reação conservadora: "o grupo capitalista do cinema brasileiro hoje, que é formado por Luiz Carlos Barreto, Bruno Barreto, Arnaldo Jabor, Walter Clark e Carlos Diegues, é oriundo do Cinema Novo"; e os antigos comunistas agora são a cabeça pensante da indústria cultural: "os intelectuais e artistas comunistas, ligados ao PC, foram para a Rede Globo". ${ }^{2}$

Nesta entrevista, o último Glauber, já bem próximo de sua morte, deixa claro seu projeto cultural (que em grande medida ainda era o mesmo da época anterior ao golpe militar):

acho que o debate aqui tinha de ser colocado em outro nível: o da busca da identidade nacional pela compreensão dos processos econômicos e culturais da colonização. (...) E esse salto é importante, tem que se superar essa feijoada ideológica, multi-ideológica, com uma visão clara do problema. ${ }^{13}$

Ora, a "feijoada ideológica" era um sinônimo para a "Geleia geral", um dos pontos centrais da ideologia tropicalista. O que Glauber percebe é que a "feijoada ideológica" promovida pelo Tropicalismo afastava a "clareza" do problema brasileiro, qual seja: "a compreensão dos processos econômicos e culturais da colonização". O que era exceção virou regra: "aqui você tem que adorar Deus, MDB, Flamengo, e ser fã de Maria Bethânia"14. A MPB, vanguarda crítica dos anos 1960, passou a liderar (ao lado do futebol e da política de centro) o conformismo nacional, uma vez liquidado seu aspecto revolucionário.

11 ROCHA, Glauber. Entrevista. In: GASPARI, Elio; HOLLANDA, Heloisa Buarque de; e VENTURA, Zuenir. 7o/8o: cultura em trânsito. Rio de Janeiro: Ed. Aeroplano, 2000. p. 156-157.

12 ROCHA, Glauber. Idem, p. 159-16o.

13 Idem, ibidem, p. 163-167.

14. Idem, ibidem, p. 161 . 
O que restou foi uma leitura ingenuamente antropofágica da "feijoada", da "geleia geral" brasileira, agora facilmente incorporada e agendada como negócio pela indústria cultural. Perdeu-se seu conteúdo emancipatório de tal modo que o ex-tropicalista agora pode ser descrito, em plena ditadura militar, que outrora o perseguiu e exilou, como um reacionário irresponsável. O diagnóstico de época feito por Glauber lembra em muito a montagem do grotesco nacional feita pelas melhores composições tropicalistas (com a diferença de que eles agora são parte interna desse grotesco nacional): "intelectual aqui é um palhaço da burguesia, são as mesmas figuras da revista Interview, das colunas sociais de $O$ Globo (...). Show da Gal Costa, espetáculo de Ney Matogrosso, teatro de Dias Gomes é tudo uma porcaria só" ${ }^{15}$. O fato é que o século XXI irá corroborar cada um dos pontos da crítica glauberiana.

Com a globalização e a consolidação do "pensamento único", uma nova onda de "cosmopolitismo" de fachada surgiu nos anos 1990 para dinamitar, mais uma vez, o novo espírito moderno brasileiro. Aderindo ao regime globalitário que jogou o Estado na era da "privatização" e "flexibilização" da barbárie, a "elite" política, intelectual e financeira bem-pensante garantiu sua hegemonia e repôs, uma vez mais, a modernização exclusiva para si. Do outro lado, os pobres também puderam "avançar" em direção à mendicância, à "terceirização" ou ao assalto à mão armada. E dentro das prisões de segurança cada vez mais "máxima" puderam racionalizar sua ação para dentro do mundo que os excluiu. Do CPC chegamos ao PCC.

Por isso tudo, enquanto reinava a selvageria "antropofágica" da vida social e cultural do início do século XXI, o Tropicalismo em ascensão reforçava sua mitologia, com bons motivos. Em 2003 Caetano Veloso se apresentou na cerimônia de entrega do Oscar. Cantou uma canção em inglês, composta por Elliot Goldenthal e Julie Taymor para o filme Frida, cinebiografia hollywoodiana da pintora Frida Kahlo (que virou moda desde que foi colecionada pela cantora Madona). Sua voz então acompanhava um filme banalíssimo, que tratava, com os clichês do gênero, a obra da pintora - trotskista, manca e bissexual - interpretada por Salma Hayek, atriz de origem mexicana que faz parte da reserva de cota para o estereótipo latino-americano. Na época, a imprensa tratou o fato com pouco estardalhaço: ora de modo nacionalista (apontando a conquista de um "brasileiro"), ora de modo ressentido, insistindo em destacar o "nervosismo" do cantor em cena. Não ocorreu a ninguém notar que se tratava de

15 Idem, ibidem, p. 161.

148

revista ieb $n_{54} 2012$ set./mar. p. I39-I50 
um momento decisivo para a cultura moderna brasileira: o Tropicalismo chegava aonde sempre quis chegar, ao topo da indústria cultural.

Nos museus e galerias de arte do mundo todo a vertente neoconcreta, normalmente associada como braço da "revolução tropicalista", também ia se tornando central. Em 1998, a Bienal de São Paulo, cujo tema foi "Antropofagia", não apenas prestou uma homenagem às ideias oswaldianas, mas também ajudou a sacramentar a leitura globalizante e a atualização destas ideias no universo da indústria cultural feita pelo Tropicalismo ${ }^{16}$. Neste momento, as figuras e as obras de Hélio Oiticica e Lygia Clark já tomavam o circuito internacional da arte. Mais de quarenta anos depois, o discurso pós-moderno descobria na teoria do "não objeto", no sensorialismo e nas intervenções e happenings da vanguarda neoconcreta brasileira uma espécie de pré-história da forma da arte contemporânea depois das vanguardas. Assim, seja na música pop, seja nas artes visuais, as vanguardas brasileiras dos anos 1960 pareciam definir o mundo que não acreditava mais em definições.

Essa união conceitual entre o Tropicalismo e o Neoconcretismo foi consolidada internacionalmente em 2006, quando foi inaugurada em Londres a exposição Tropicália - A revolution in Brazilian culture, no Barbican Center. Organizado por Carlos Basualdo, o evento reuniu artes plásticas, uma mostra de cinema e apresentações musicais (contando inclusive com um estranho "renascimento" do ultratropicalista grupo Os Mutantes). Literalmente pensada "para inglês ver", a exposição sacramentava o fim da transgressão e a consolidação do Tropicalismo como um "estilo" dominante no mercado das formas globais. Um jornalista que acompanhou a exposição escreveu:

como se vê, tropicalismo é hoje um guarda-chuva enorme e generoso, fonte legítima de inspiração e, também, álibi condescendente para qualquer "mistura" de níveis de cultura, referências pop e eruditas, tradição e, vá lá, transgressão. Mas a verdadeira exposição começa no Palácio de Buckhingham, que desde sexta-feira passada exibia frondosas bandeiras brasileiras à espera do presidente-operário, convidado de honra de Sua Majestade. Foi há quase quarenta anos que um poeta desfolhou a bandeira. Agora a manhã tropical está mais para day after. Batmacumba ê-ê.. ${ }^{17}$

16 Em outro estudo analisei essa questão mais de perto. Cf. ALAMBERT, Francisco; CANHÊTE, Polyana. Bienais de São Paulo: da era do Museu à era dos curadores. São Paulo: Boitempo, 2004.

17 “Yes, nós somos vanguarda". Paulo Roberto Pires. 7 mar. 20o6, publicada no site No Mínimo. 
Em resumo: os êxitos dos tropicalistas em todos os campos são notáveis. Tanto e de tal forma que, mesmo depois que todas as condições históricas de seu surgimento desapareceram, podemos dizer que a "verdade tropical" se tornou a ideologia cultural hegemônica no Brasil, e se lançou ao mundo. Por um lado, seu aspecto contestador dos costumes da vida burguesa da periferia do capitalismo desapareceu. Por outro, sua feroz crítica aos pressupostos da esquerda cultural, sempre acusada de "patrulhamento" (crítica que em seus piores momentos pouco se diferenciava da histeria anticomunista da própria ditadura), e sua apologia da indústria cultural como uma realidade tanto inescapável quanto atualizadora permitiram a sobrevida da "forma tropicalista" e sua escalada vertiginosa ao topo do poder hegemônico.

Assim, o mundo "pós-moderno", neoliberal, antirrevolucionário, multicultural etc. convive com uma versão quarentona do Tropicalismo. Entender como se dá a dialética dessa "tradição" (agora tanto razão de Estado quanto centro da indústria cultural) e dessa "modernidade" é central para se compreender o futuro da questão cultural no Brasil, sobretudo no que tange à possibilidade de revitalização de uma cultura de "resistência" que a razão tropicalista implodiu. Isso é uma tarefa para muitos. A proposta de grupos de teatro de recuperar a tradição épica e dialética, enfrentar a produção de cultura como ato político coletivo, contrariando os imperativos da indústria cultural e do domínio das leis de "incentivo" à cultura atreladas aos departamentos de marketing das empresas (como a famigerada Lei Rouanet), representa a tentativa de elaboração de uma arte nova, que ignora o niilismo bem posto que o Tropicalismo nos ensinou a adorar. 